\title{
Information Restitution in the Optical Memories using a Thin Layer of the Vanadium Dioxide
}

\author{
Mohammed Zouini ${ }^{1 \% *}$, Abderrahim Ben Chaib ${ }^{1}$, Abdesselam Mdaa ${ }^{1}$ and El Mehdi el Khattabi ${ }^{2}$ \\ ${ }^{1}$ Laboratory of the thin layers and surface treatment by plasma, Ecole Normale Supérieure de Fès. Fez 30000, Morocco. \\ ${ }^{2}$ Laboratory for Integration of Advanced Systems and Technologies-University Sidi Mohamed ben Abdellah-Faculty of Sciences Dhar El
} Mehraz, Fez, 30000, Morocco

Received 20 March 2018; Accepted 4 November 2018

\begin{abstract}
Today, nanotechnologies have become a very important part of our daily life, contributing to the significant improvement of many technological and industrial sectors such as information technology, internal security, medicine, transport, energy, food safety, environmental sciences and many others. This technology allows materials to be processed at the nanoscale. We have studied the vanadium dioxide $\mathrm{VO} 2$, a material that is currently being researched in the development of new technologies, and the possibility of integrating nanoparticles of this material into the energy field, knowing that it's considered an intelligent material. Each cooling followed by heating of such a material generates a hysteresis loop, the area of this loop represents the energy dissipated in this material. In this paper, we will mathematically model this loop to determine the dissipated energy $\mathrm{E}$ that can be reduced or reused as an energy source. We compared the energy dissipated in pure vanadium dioxide and doped according to the two types of doping n-type with $5 \%$ tungsten (W), p-type with $15 \%$ chromium $(\mathrm{Cr})$, we find that doping in general results in a decrease in the energy dissipated in this material compared to the pure state.
\end{abstract}

Keywords: High speed circuits, Right angle bend, FDTD and MNA methods, Eye Diagram, noisy CMOS.

\section{Introduction}

In the context of scientific and technological change, nanotechnology has become the main research focus of all researchers. Many benefits of nanotechnology depend on the ability to adapt material structures to scales below 100 nanometers to obtain nanomaterials that are composed of nanoparticles, which greatly expands the concepts of materials science. These nanoparticles are included as nano additives in different fields. The titanium dioxide nanoparticles $\mathrm{TiO}_{2}$, in the sunscreens [1], the nanoparticles in the food packaging [2]; the zinc oxide nanoparticles $\mathrm{ZnO}$, in the sunscreens, in the exterior coatings, and in the paintings [1,3]; the cerium oxide nanoparticles $\mathrm{CeO}_{2}$ [4,5] acting as catalyst for the fuels.

This gives rise to new discoveries such as intelligent materials, there are particularly materials that have the ability to receive information from their environment and interact with this environment by changing their properties (optical, electrical, mechanical, etc.) following the external stimuli. The vanadium dioxide $\mathrm{VO}_{2}$ was discovered over 50 years ago by F. J. Morin [6], that highlighted its reversible phase transition [7-13] from the semiconductor state to its metallic state at a transition temperature of $\theta_{t}=68^{\circ} \mathrm{C}$.

This phase transition causes enormous changes in the optical and electrical properties of this material [14-18] in the near infrared. Below the transition temperature the resistivity [19] decreases exponentially as the temperature

*E-mail address: mohammed.zouini@usmba.ac.ma

ISSN: $1791-2377$ @ 2018 Eastern Macedonia and Thrace Institute of Technology. All rights reserved. doi:10.25103/jestr.115.04 increases. At the temperature $\theta_{\mathrm{t}}=68^{\circ} \mathrm{C}$, the resistance abruptly falls with three orders of magnitude. Beyond $90^{\circ} \mathrm{C}$, the resistivity is stabilized in $0.05 \Omega \mathrm{cm}$. In the infra-red, the optical constants undergo a definitely distinguished variation like the transmittivity $\mathrm{T}[20,21]$. In this context, we observe a significant variation in the transmittivity of the $\mathrm{VO}_{2}$ film between the insulating state characterized by a high transmittivity $\left(42 \%\right.$ at $\left.5^{\circ} \mathrm{C}\right)$ and the metallic state, where the transmittivity is very low $\left(5 \%\right.$ at $\left.100^{\circ} \mathrm{C}\right)$.

This transition is effected in a very short time, in the order of a few nanoseconds. Below $\theta_{\mathrm{t}}\left(\theta<68^{\circ} \mathrm{C}\right)$, the $\mathrm{VO}_{2}$ behaves as an insulator with a monoclinic crystalline structure where we have an alternation of the short v-v $(2.65$ $\AA)$ and long (3.12 $\AA$ ) bonds; this led to a doubling of the parameter $\mathrm{c}$ and the opening of the gap [22,23], in the conduction band $3 \mathrm{~d}$ of the vanadium [24] and a high transmittivity, but above $\theta_{\mathrm{t}}\left(\theta>68^{\circ} \mathrm{C}\right)$, the material is suddenly transformed and acquires the behaviour of a metal with a rutile tetragonal quadratic structure, characterized by octahedra chains $\mathrm{VO}_{6}$ [25], joined by the peaks along the axis c with distances $\mathrm{d}_{\mathrm{v}-\mathrm{v}}=2.88 \AA$ and a low transmittivity. In order to introduce this application in everyday life, it's necessary to lower the critical temperature $\theta_{t}$ of vanadium dioxide by doping it with different elements [26-30]. Indeed, the doping of a thin layer of $\mathrm{VO}_{2}$ with different doses of tungsten $\mathrm{W}$ [31] lowers the transition temperature to around $28^{\circ} \mathrm{C}$.

In the infrared spectrum, during heating and cooling of this material, a hysteresis loop appeared. In physics, a hysteresis loop represents a quantity of energy dissipated $[8,15]$ in this material by traversing this loop completely or partially. We will try to make a mathematical modeling of 
the optical hysteresis loop [32,33], throughout the phase transition $\mathrm{VO}_{2}$ (semiconductor) $\rightleftarrows \mathrm{VO}_{2}$ (metal), during a heating followed by a cooling between the temperatures $\theta_{1}=$ $30^{\circ} \mathrm{C}$ and $\theta_{2}=100^{\circ} \mathrm{C}$ or between $\theta_{1}=30^{\circ} \mathrm{C}$ and $\theta_{\mathrm{i}}$ such as $\theta_{1}$ $<\theta_{\mathrm{i}}<\theta_{2}$.

In this study, we simulated and analyzed the energy dissipated in pure and doped state with $5 \% \mathrm{~W}$ and $15 \% \mathrm{Cr}$ [34] of vanadium dioxide, which makes this material a promising candidate in various fields. In computing; the use of this dissipated energy as a means of increasing the speed of data storage in optical memories and storage masses. In the energy field; the use of vanadium dioxide nanoparticles as nano additives in fuels to reduce the energy dissipated by combustion.

\section{Method}

We have based on the bibliographic results referenced by $[31,34]$, concerning the study of the transmittivity $\mathrm{T}$ of a thin layer of vanadium dioxide.

According to Fig.1, we modelled the mathematical expression of the transmittivity $\mathrm{T}$ for the pure and doped state $(5 \% \mathrm{~W}$ and $15 \% \mathrm{Cr})$ of vanadium dioxide in different temperature intervals $\theta$.

In the pure state of $\mathrm{VO}_{2}$, for a temperature of $5^{\circ} \mathrm{C}<\theta<$ $30^{\circ} \mathrm{C}$, the transmittivity expression $\mathrm{T}$, in heating and cooling is:

$$
\left\{\begin{array}{c}
\mathrm{T}=\mathrm{a} \theta+\mathrm{C}_{1} \\
\mathrm{a} \rightarrow 0 ; \mathrm{C}_{1}=\text { cste }
\end{array}\right.
$$

For a temperature of $5^{\circ} \mathrm{C}<\theta<30^{\circ} \mathrm{C}$ the transmittivity is constant and takes the value $\mathrm{T}=\mathrm{C}_{1}=40.3 \%$

When the temperature interval boundaries $\theta_{1}<\theta<\theta_{2}$ takes the values $\theta_{1}=30^{\circ} \mathrm{C}$ and $\theta_{2}=100^{\circ} \mathrm{C}$, the transmittivity curve $\mathrm{T}$ becomes exponential, and the mathematical expressions $\mathrm{T}$ in heating and cooling are:

While heating:

$$
\left\{\begin{array}{c}
\mathrm{T}_{1}=A \exp \left(-\mathrm{b}_{1} \theta\right) \\
\mathrm{b}_{1}=\text { cste }>0 ; A=\text { cste }
\end{array}\right.
$$

While cooling:

$$
\left\{\begin{array}{c}
\mathrm{T}_{2}=\mathrm{B} \exp \left(-\mathrm{b}_{2} \theta\right) \\
\mathrm{b}_{2}=\text { cste }>0 ; \mathrm{B}=\text { cste }
\end{array}\right.
$$

$\mathrm{A}, \mathrm{B}, \mathrm{b}_{1}$ et $\mathrm{b}_{2}$ are constants which we can graphically determine, starting from the curve of hysteresis: $\mathrm{A}=$ $4.100765 \% ; \mathrm{B}=3.956749 \% ; \mathrm{b}_{1}=0.040547\left({ }^{\circ} \mathrm{C}\right)^{-1} ; \mathrm{b}_{2}=$ $0.0532\left({ }^{\circ} \mathrm{C}\right)^{-1}$.

For the doped state of $\mathrm{VO}_{2}$ by $5 \% \mathrm{~W}$, the temperature boundaries $\theta_{1}<\theta<\theta_{2}$, takes the values $\theta_{1}=5^{\circ} \mathrm{C}$ and $\theta_{2}=$ $65^{\circ} \mathrm{C}$, and the mathematical expressions $\mathrm{T}$ in heating and cooling are:

While heating:

$$
\left\{\begin{array}{c}
\mathrm{T}_{1}=A \exp \left(-\mathrm{b}_{1} \theta\right) \\
\mathrm{b}_{1}=\text { cste }>0 ; A=\text { cste }
\end{array}\right.
$$

While cooling:

$$
\left\{\begin{array}{c}
\mathrm{T}_{2}=\mathrm{B} \exp \left(-\mathrm{b}_{2} \theta\right) \\
\mathrm{b}_{2}=\text { cste }>0 ; \mathrm{B}=\text { cste }
\end{array}\right.
$$

Where,

$\mathrm{A}=0.508193 \% ; \mathrm{B}=0.543532 \% ; \mathrm{b}_{1}=0.033509\left({ }^{\circ} \mathrm{C}\right)^{-1} ; \mathrm{b}_{2}=$ $0.04621\left({ }^{\circ} \mathrm{C}\right)^{-1}$

For the doped state of $\mathrm{VO}_{2}$ by $15 \% \mathrm{Cr}$, the temperature boundaries $\theta_{1}<\theta<\theta_{2}$, takes the values $\theta_{1}=53^{\circ} \mathrm{C}$ and $\theta_{2}=$ $117^{\circ} \mathrm{C}$, and the mathematical expressions $\mathrm{T}$ in heating and cooling are:

While heating:

$$
\left\{\begin{array}{c}
\mathrm{T}_{1}=A \exp \left(-\mathrm{b}_{1} \theta\right) \\
\mathrm{b}_{1}=\text { cste }>0 ; A=\text { cste }
\end{array}\right.
$$

While cooling:

$$
\left\{\begin{array}{c}
\mathrm{T}_{2}=\mathrm{B} \exp \left(-\mathrm{b}_{2} \theta\right) \\
\mathrm{b}_{2}=\text { cste }>0 ; \mathrm{B}=\text { cste }
\end{array}\right.
$$

Where,

$$
\begin{aligned}
& \mathrm{A}=4.045339 \% ; \mathrm{B}=16.135495 \% ; \mathrm{b}_{1}=0.036154\left({ }^{\circ} \mathrm{C}\right)^{-1} ; \\
& \mathrm{b}_{2}=0.048012\left({ }^{\circ} \mathrm{C}\right)^{-1}
\end{aligned}
$$

We calculate the surface I ranging between two curves 1 and 2 of the hysteresis loop in the $\mathrm{VO}_{2}$ material during this variation of up-and-down as shown in scheme 1 , by the equation (1):

$|I|=\frac{E_{\text {dissipated }}}{h v}=\frac{E_{\text {dissipated }}}{\hbar \omega}$

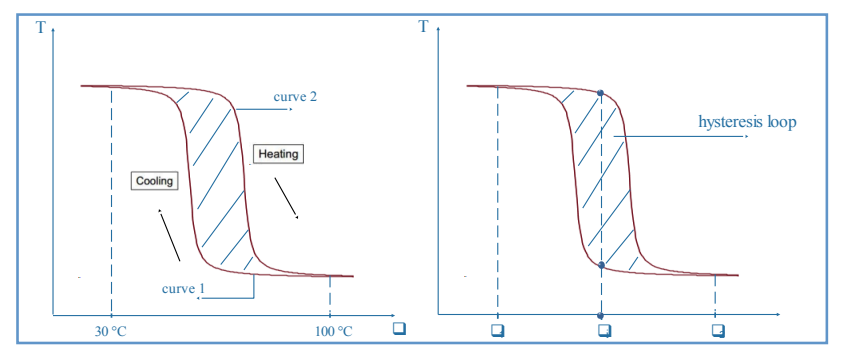

Scheme. 1 The variation of the transmittivity T of a thin layer of the vanadium dioxide with the hysteresis loop

we pose:

$I_{1}=\int_{\theta_{1}}^{\theta_{2}} T_{1} d \theta ; I_{2}=\int_{\theta_{2}}^{\theta_{1}} T_{2} d \theta$

$\mathrm{I}=\mathrm{I}_{2}-\mathrm{I}_{1}$

Thus:

$I=-\int_{\theta_{1}}^{\theta_{2}} T_{1} d \theta+\int_{\theta_{2}}^{\theta_{1}} T_{2} d \theta$

$I=-\int_{\theta_{1}}^{\theta_{2}} A \exp \left(-b_{1} \theta\right) d \theta-\int_{\theta_{1}}^{\theta_{2}} B \exp \left(-b_{2} \theta\right) d \theta$

$I=\frac{A}{b_{1}}\left[\exp \left(-b_{1} \theta\right)\right]_{\theta_{1}}^{\theta_{2}}+\frac{B}{b_{2}}\left[\exp \left(-b_{2} \theta\right)\right]_{\theta_{2}}^{\theta_{1}}$

$\mathrm{I}=\frac{\mathrm{A}}{\mathrm{b}_{1}}\left(\exp \left(-\mathrm{b}_{1} \theta_{2}\right)-\exp \left(-\mathrm{b}_{1} \theta_{1}\right)\right)$

$+\frac{\mathrm{B}}{\mathrm{b}_{2}}\left(\exp \left(-\mathrm{b}_{2} \theta_{2}\right)-\exp \left(-\mathrm{b}_{2} \theta_{1}\right)\right)$ 
$I=\frac{A}{b_{1}}\left(e^{-b_{1} \theta_{2}}-e^{-b_{1} \theta_{1}}\right)+\frac{B}{b_{2}}\left(e^{-b_{2} \theta_{2}}-e^{-b_{2} \theta_{1}}\right)$

The dissipated energy in this material during this hysteresis loop is:

$$
\mathrm{E}_{\text {dissipated }}=|\mathrm{I}| \cdot \mathrm{h} v
$$

For $\theta_{1}<\theta_{i}<\theta_{2}$

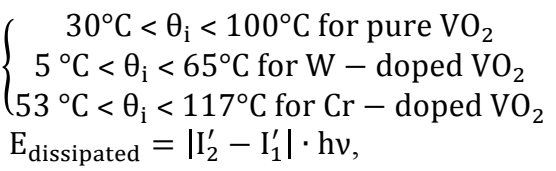

Where:

$$
\begin{aligned}
& \mathrm{I}_{1}^{\prime}=\int_{\theta_{1}}^{\theta_{\mathrm{i}}} \mathrm{T}_{1} \mathrm{~d} \theta ; \mathrm{I}_{2}^{\prime}=\int_{\theta_{2}}^{\theta_{\mathrm{i}}} \mathrm{T}_{2} \mathrm{~d} \theta \\
& \mathrm{I}^{\prime}=\mathrm{I}_{2}^{\prime}-\mathrm{I}_{1}^{\prime}(8) \\
& \mathrm{I}_{1}^{\prime}=\int_{\theta_{1}}^{\theta_{\mathrm{i}}} \mathrm{A} \exp \left(-\mathrm{b}_{1} \theta\right) \mathrm{d} \theta ; \mathrm{I}_{2}^{\prime}=\int_{\theta_{2}}^{\theta_{\mathrm{i}}} \mathrm{B} \exp \left(-\mathrm{b}_{2} \theta\right) \mathrm{d} \theta \\
& \mathrm{I}_{1}^{\prime}=-\frac{\mathrm{A}}{\mathrm{b}_{1}}\left[\exp \left(-\mathrm{b}_{1} \theta\right)\right]_{\theta_{1}}^{\theta_{\mathrm{i}}} ; \mathrm{I}_{2}^{\prime}=-\frac{\mathrm{B}}{\mathrm{b}_{2}}\left[\exp \left(-\mathrm{b}_{2} \theta\right)\right]_{\theta_{2}}^{\theta_{\mathrm{i}}} \\
& \mathrm{I}_{1}^{\prime}=-\frac{\mathrm{A}}{\mathrm{b}_{1}}\left(\exp \left(-\mathrm{b}_{1} \theta_{\mathrm{i}}\right)-\exp \left(-\mathrm{b}_{1} \theta_{1}\right)\right) ; \mathrm{I}_{2}^{\prime} \\
& \quad=-\frac{\mathrm{B}}{\mathrm{b}_{2}}\left(\exp \left(-\mathrm{b}_{2} \theta_{\mathrm{i}}\right)-\exp \left(-\mathrm{b}_{2} \theta_{2}\right)\right)
\end{aligned}
$$

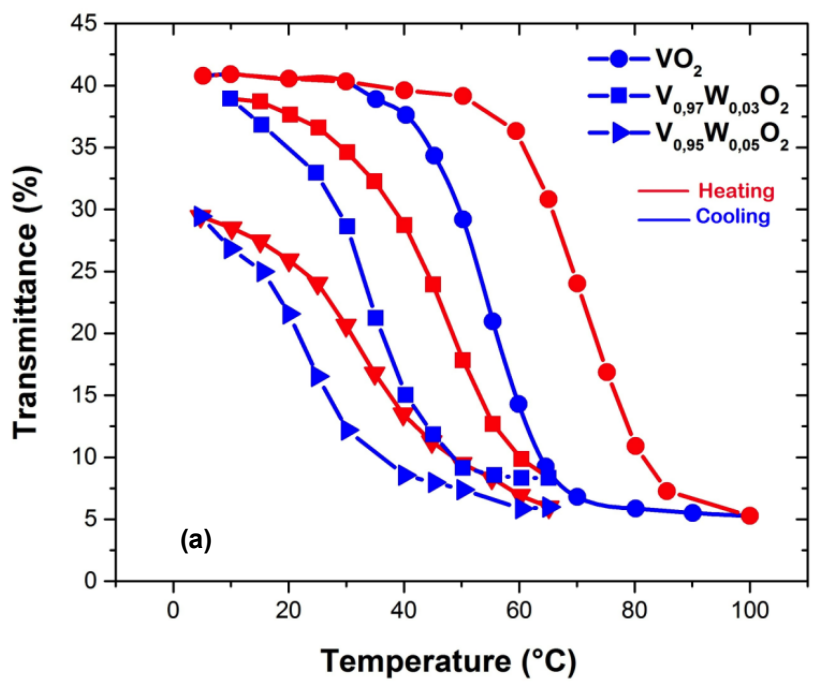

$$
\begin{aligned}
I^{\prime}=\frac{A}{b_{1}}\left(\exp \left(-b_{1} \theta_{i}\right)\right. & \left.-\exp \left(-b_{1} \theta_{1}\right)\right) \\
- & \frac{B}{b_{2}}\left(\exp \left(-b_{2} \theta_{i}\right)-\exp \left(-b_{2} \theta_{2}\right)\right)
\end{aligned}
$$

$$
\begin{aligned}
\mathrm{E}_{\text {dissipated }}=\mathrm{hv} \cdot & \mid \frac{\mathrm{A}}{\mathrm{b}_{1}}\left(\exp \left(-\mathrm{b}_{1} \theta_{\mathrm{i}}\right)-\exp \left(-\mathrm{b}_{1} \theta_{1}\right)\right) \\
& -\frac{\mathrm{B}}{\mathrm{b}_{2}}\left(\exp \left(-\mathrm{b}_{2} \theta_{\mathrm{i}}\right)\right. \\
& \left.-\exp \left(-\mathrm{b}_{2} \theta_{2}\right)\right) \mid
\end{aligned}
$$

We see that the dissipated energy $E_{\text {dissipated }}$ in the vanadium dioxide depends on two parameters: the frequency $v$ of the incidental photons and the temperature $\theta$.

From the expression of the dissipated energy $\mathrm{E}_{\text {dissipated }}$, we can extract the variation from the transmittivity $T$ according to $\theta$ for a fixed frequency $v$.

\section{Results \& Discussion}

According to this mathematical modeling of the functions which limit this optical hysteresis loop concerning the variation of the transmittivity $\mathrm{T}$ as function of the temperature $\theta$, we can calculate the dissipated energy $\mathrm{E}$ in a thin layer of the pure and $\mathrm{W}$-doped or $\mathrm{Cr}$-doped vanadium dioxide $[31,34]$, in the infra-red spectrum for a frequency $v$ or determined energy $\hbar \omega$, by completely or partially traversing this hysteresis loop as shown in Fig. 1. We note that the transmittivity $\mathrm{T}$ of this thin layer of pure and $\mathrm{VO}_{2}$ doped varies in exponential decreasing between the bounds of hysteresis but in an irreversible way during a heating followed by a cooling and reciprocally; this produced a dissipated energy in this material.

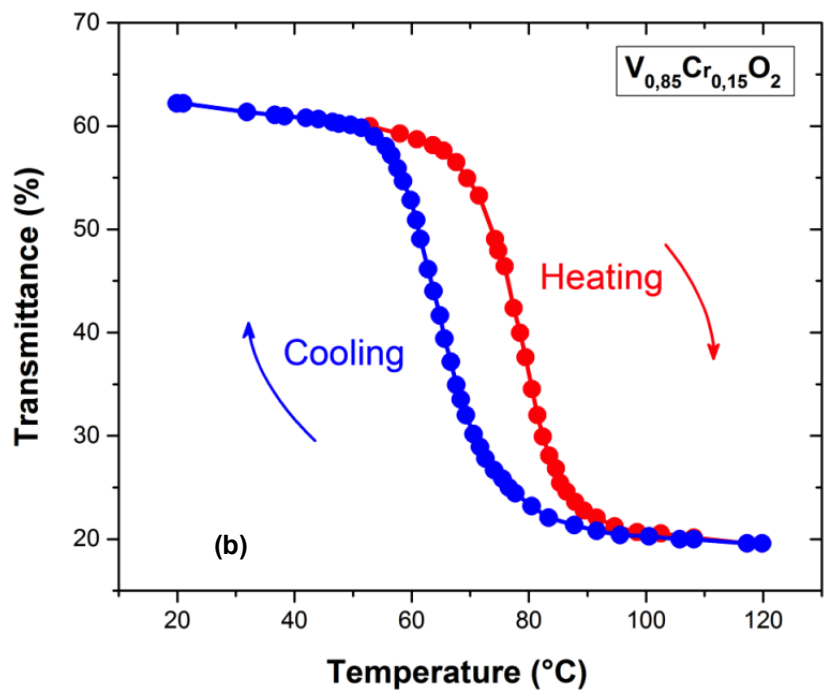

Fig. 1 Transmittivity of a thin layer of the vanadium dioxide during the heating and cooling for $\lambda=2000 \mathrm{~nm}$. (a) $\mathrm{W}$-doped $\mathrm{VO}_{2}$ by Batista et al. [31]. (b) Cr-doped $\mathrm{VO}_{2}$ by Beteille and Livage [34].

By fixing the frequency $v$ in the infra-red and by varying the temperature $\theta$ as shown in Figs. 2, 3, 4 and 5; we deduce that the energy dissipated in the $\mathrm{VO}_{2}$ intrinsic and the $\mathrm{VO}_{2}$ doped type $\mathrm{n}$ by $5 \% \mathrm{~W}$ increases if the temperature $\theta$ is increasing; this result allows us to see the decrease of the amplitude of the transmittivity $\mathrm{T}$ and to envisage the transition phase of this thin layer from the semiconductor state to the metal state and reciprocally. This dissipated energy also enables us to consult the deferent electronic transitions in the semiconductor state since it is related to light energy $\hbar \omega$ of the incidental photons for the given temperatures, and it causes the excitation of the electrons of the energy bands of pure $\mathrm{VO}_{2}$ on the one hand, and for the W- doped $\mathrm{VO}_{2}$, on the other hand, we can control the increase of this dissipated energy as a function of temperature. In the infra-red, this dissipated energy $\mathrm{E}$ in this hysteresis loop can be converted into other forms of energy which will become useful, such as the optical memories or 
the storage mass, the detectors of the infra-red, the solarwater heaters, where it is used for the temperatures of the pumps release which helps circulate the fluids in the thermal networks.
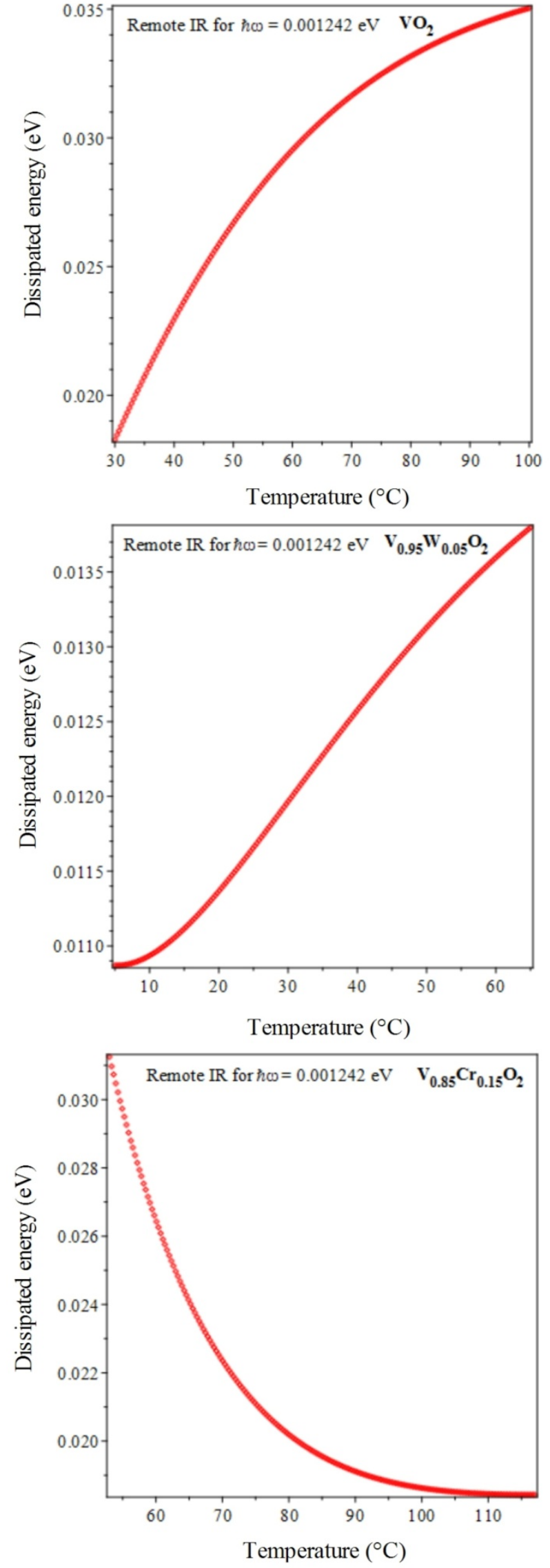

Fig. 2 The dissipated energy according to the temperature in the remote infra-red for $\hbar \omega=0.001242 \mathrm{eV}$
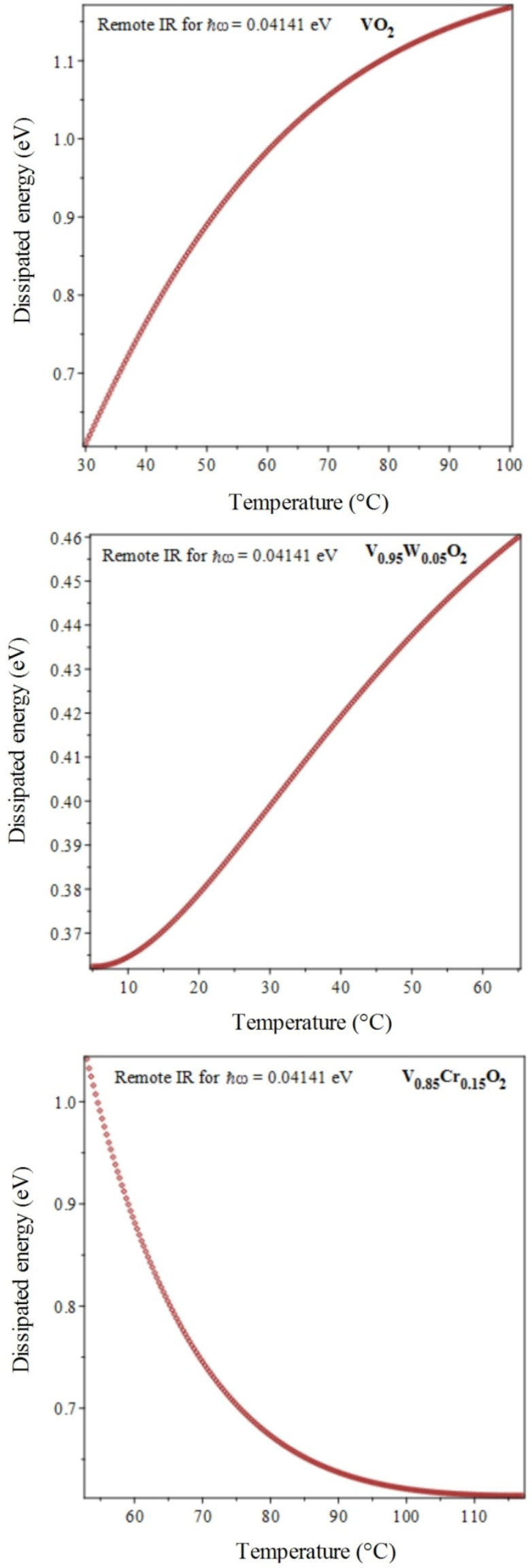

Fig. 3 The dissipated energy according to the temperature in the remote infra-red for $\hbar \omega=0.04141 \mathrm{eV}$. 
Mohammed Zouini, Abderrahim Ben Chaib, Abdesselam Mdaa and El Mehdi el Khattabi/

Journal of Engineering Science and Technology Review 11 (5) (2018) 26 - 34
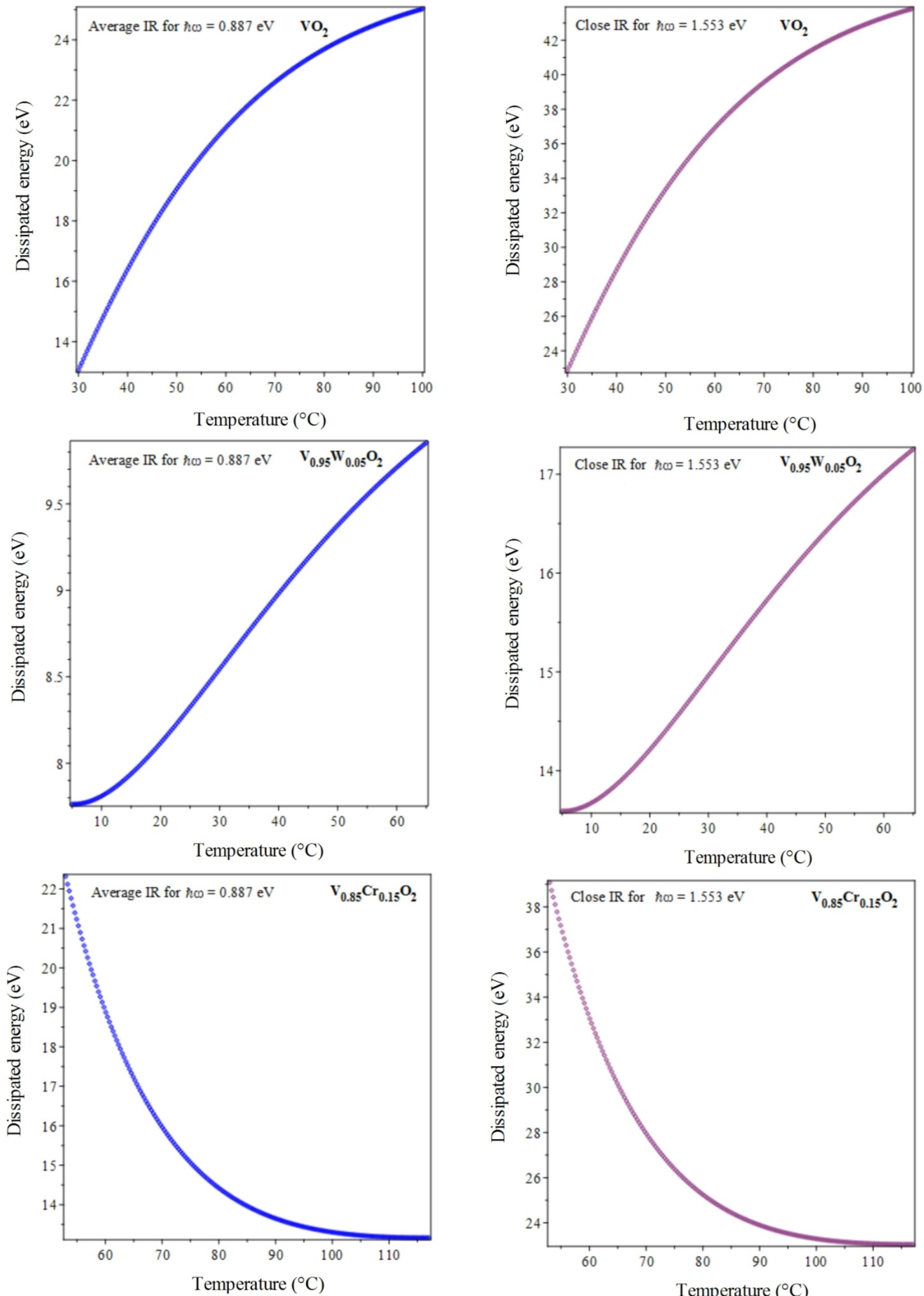

Fig. 4 The dissipated energy according to the temperature in the average infra-red for $\hbar \omega=0.887 \mathrm{eV}$

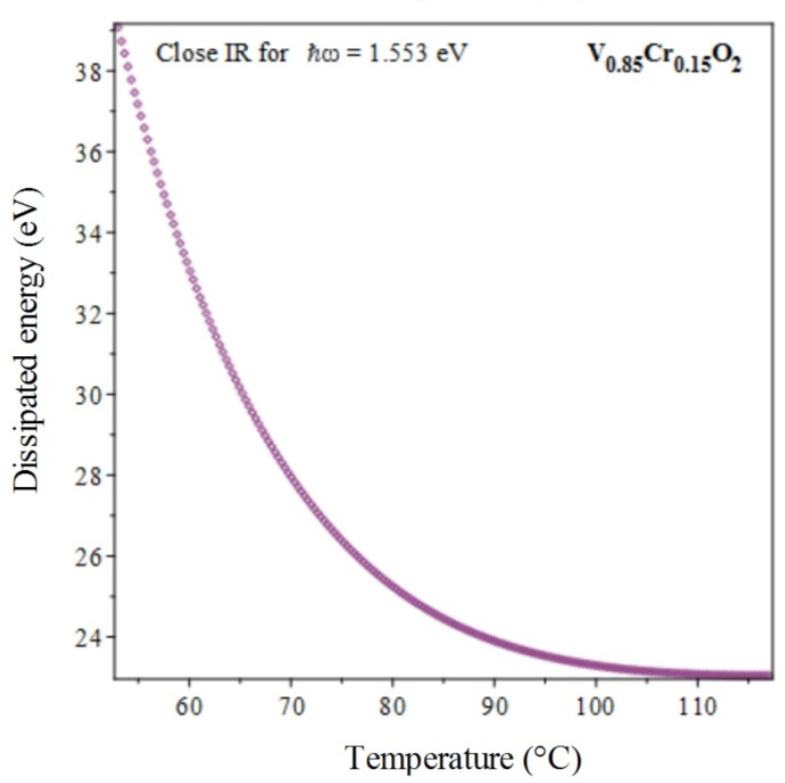

Fig. 5 The dissipated energy according to the temperature in the close infra-red for $\hbar \omega=1.553 \mathrm{eV}$.

In the case of the p-type doping of $\mathrm{VO}_{2}$ by $15 \% \mathrm{Cr}$, there is an exponential decrease in the energy dissipated in this 
material due to the excess of the holes caused by this type of doping. It can be introduced in applications such as commutators, transistors.

If we carry out a frequency of 50 or 1000 times or more of this hysteresis loop concerning the transmittivity $\mathrm{T}$ of this thin layer of $\mathrm{VO}_{2}$, we notice that the dissipated energy $\mathrm{E}$ becomes important in value which we can transform according to our utilities or special needs. Therefore, it is necessary to know how and to be able to calculate this dissipated energy in this material during a thermochromic phase transition.
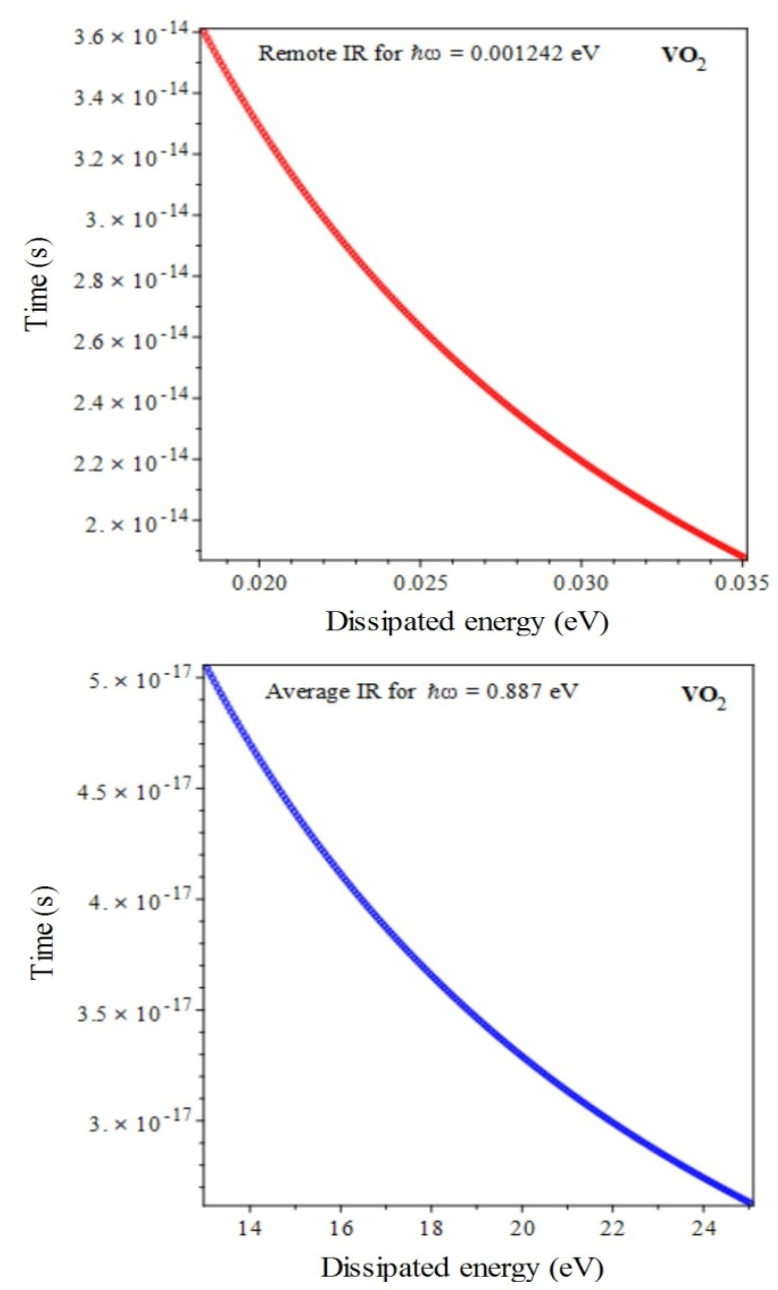

According to the uncertainty principle of Heisenberg [35], $\Delta \mathrm{E} \cdot \Delta \mathrm{t} \cong \hbar / 2$ or $\Delta \mathrm{x} \cdot \Delta \mathrm{p} \cong \hbar / 2$, this energy can be dissipated in the optical memories (or the storage mass) of the thin layer of the pure or doped vanadium dioxide so as to be able to calculate the time $\Delta \mathrm{t}$ of the information storage. Indeed, if the energy $\Delta \mathrm{E}$ is weak then $\Delta \mathrm{t}$ is large and conversely. This is realizable in the infra-red spectrum, as it is shown in Tables.1, 2, and 3 which are extracted respectively of Figs. 6, 7 and 8 . We note that the restitution time $\Delta \mathrm{t}$ increases by n-type doping, while the p-type doping does not have a great influence on this time
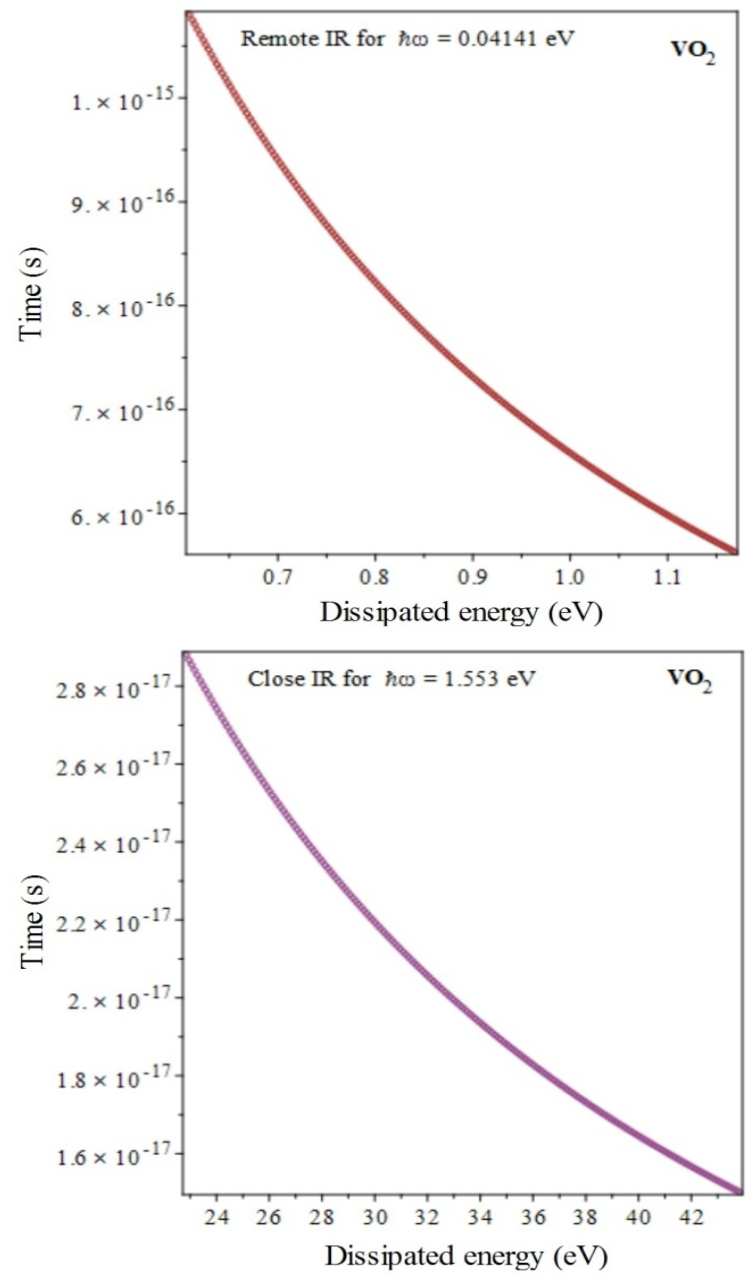

Fig. 6 Variation of the time of storage $\Delta \mathrm{t}$ according to the energy dissipated in the infra-red for pure $\mathrm{VO}_{2}$.

Table 1.Some values of the storage time according to the energy dissipated in the I.R for pure $\mathrm{VO}_{2}$

\begin{tabular}{c|c|c}
\hline $\begin{array}{c}\text { Energy of the photon in the I.R } \boldsymbol{\omega} \\
(\mathbf{e V})\end{array}$ & Dissipated energy E (eV) & Storage time $\Delta \mathbf{t}(\mathbf{n s})$ \\
\hline 0.001242 & 0.034 & $2 \cdot 10^{-5}$ \\
0.04141 & 1.15 & $5.6 \cdot 10^{-7}$ \\
0.887 & 25 & $2.6 \cdot 10^{-8}$ \\
1.553 & 43 & $1.5 \cdot 10^{-8}$ \\
\hline
\end{tabular}

Table 2. Some values of the storage time according to the energy dissipated in the I.R for W-doped $\mathrm{VO}_{2}$

\begin{tabular}{c|c|c}
\hline $\begin{array}{c}\text { Energy of the photon in the I.R } \boldsymbol{\omega} \\
(\mathbf{e V})\end{array}$ & Dissipated energy E (eV) & Storage time $\Delta$ t (ns) \\
\hline 0.001242 & 0.013 & $4.77 \cdot 10^{-5}$ \\
0.04141 & 0.46 & $1.43 \cdot 10^{-6}$ \\
0.887 & 9.85 & $6.68 \cdot 10^{-8}$ \\
1.553 & 17.25 & $3.81 \cdot 10^{-8}$ \\
\hline
\end{tabular}


Mohammed Zouini, Abderrahim Ben Chaib, Abdesselam Mdaa and El Mehdi el Khattabi/ Journal of Engineering Science and Technology Review 11 (5) (2018) 26 - 34
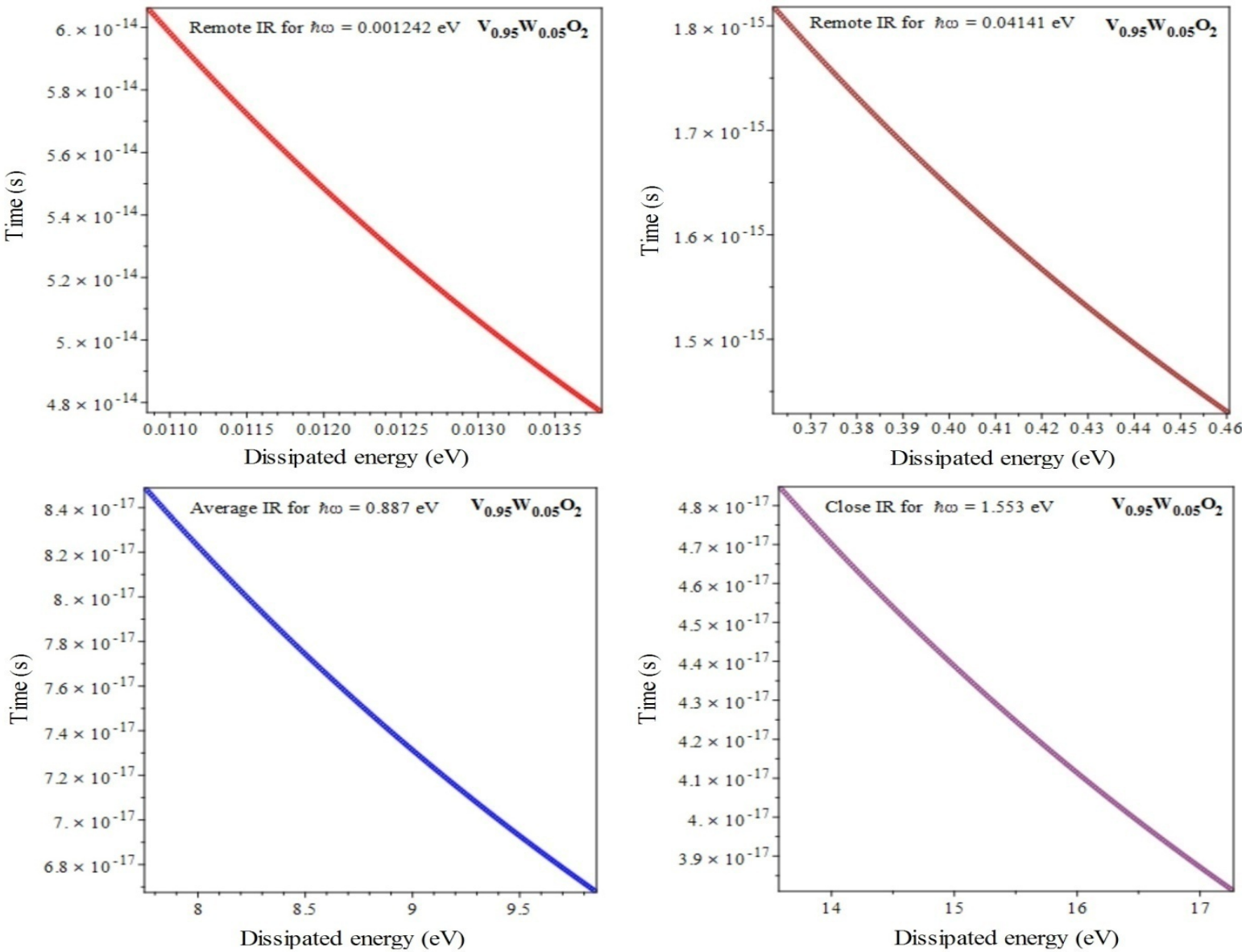

Fig. 7 Variation of the time of storage $\Delta t$ according to the energy dissipated in the infra-red for W-doped $\mathrm{VO}_{2}$.
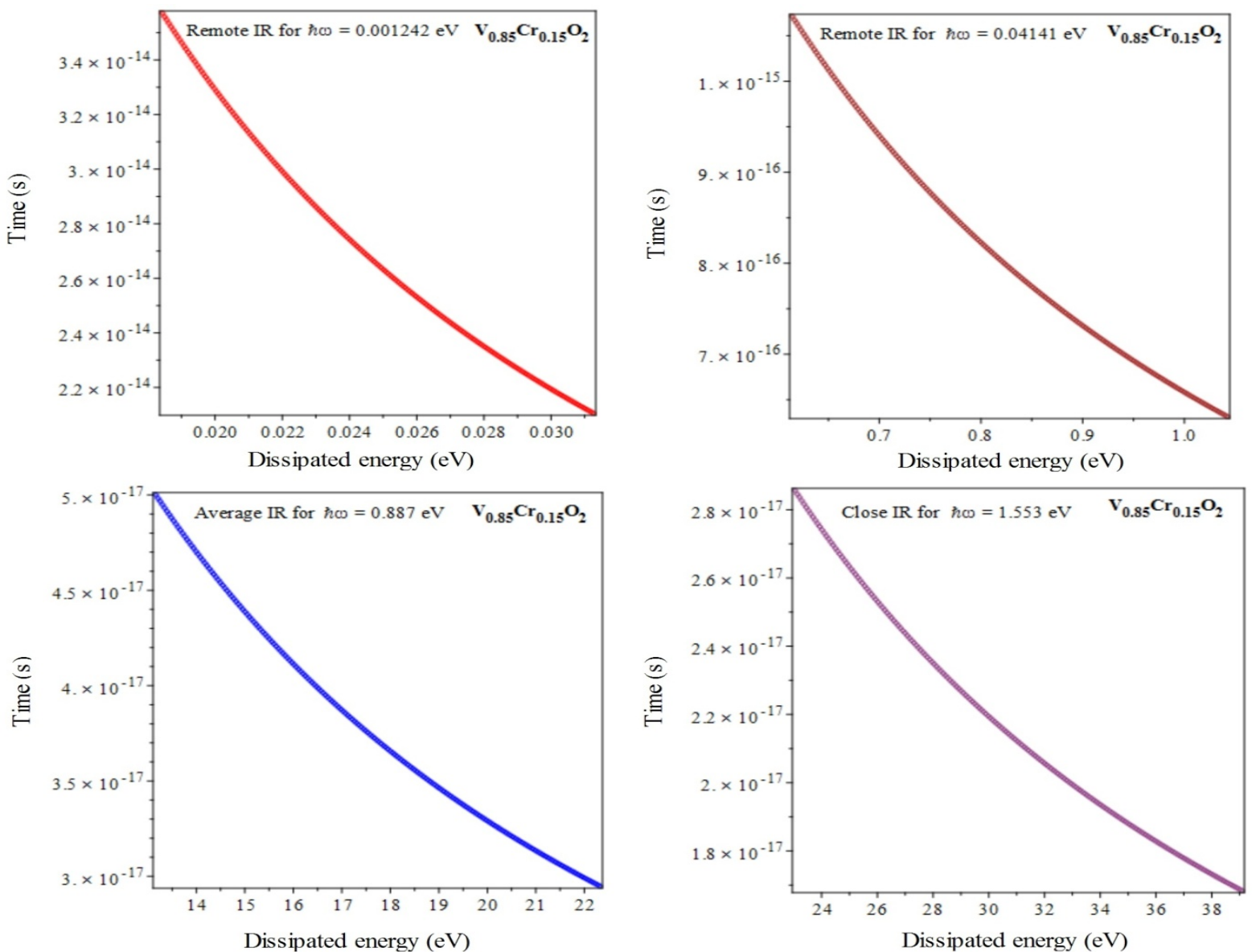

Fig. 8 Variation of the time of storage $\Delta \mathrm{t}$ according to the energy dissipated in the infra-red for $\mathrm{Cr}$-doped $\mathrm{VO}_{2}$. 
Table 3.Some values of the storage time according to the energy dissipated in the I.R for Cr-doped $\mathrm{VO}_{2}$

\begin{tabular}{c|c|c}
\hline $\begin{array}{c}\text { Energy of the photon in the I.R } \boldsymbol{\omega} \\
(\mathbf{e V})\end{array}$ & Dissipated energy E (eV) & Storage time $\Delta \mathbf{t}(\mathbf{n s})$ \\
\hline 0.001242 & 0.032 & $2.1 \cdot 10^{-5}$ \\
0.04141 & 1.041 & $6.32 \cdot 10^{-7}$ \\
0.887 & 22.31 & $3 \cdot 10^{-8}$ \\
1.553 & 39.07 & $1.68 \cdot 10^{-8}$ \\
\hline
\end{tabular}

We note that the doping of a thin layer of $\mathrm{VO}_{2}$ decreases the transmittivity. The area of the hysteresis loop decreases by the tungsten $\mathrm{W}$-doped $\mathrm{VO}_{2}$ film, which makes it possible to increase the storage time $\Delta t$ of the information in the storage masses.

For $\mathrm{VO}_{2}$ tungsten doping, it can be seen that the dissipated energy increases as the incident photons' energy increases in the infrared, and for each area of the I.R, we have:

$$
\frac{\Delta \mathrm{t}\left(\mathrm{W}-\text { doped } \mathrm{VO}_{2}\right)}{\Delta \mathrm{t}\left(\text { pure } \mathrm{VO}_{2}\right)} \cong 2.5
$$

In this study, we noted that the storage time $\mathrm{t}$ in a $\mathrm{W}$ doped vanadium dioxide thin film is a multiple of the storage time in a pure vanadium dioxide thin film by a factor of about 2.5.

For the Cr-doped $\mathrm{VO}_{2}$, we find that this time $\Delta \mathrm{t}$ is of the same order of magnitude as that of pure $\mathrm{VO}_{2}$.

\section{Conclusion}

This study focuses on an intelligent material characterized by these thermochromic properties, namely the vanadium dioxide. A cooling operation followed by heating of this material is expressed by a hysteresis loop. The area of this loop represents the energy dissipated in this material. To facilitate the understanding of this phenomenon, we have mathematically modelled this energy dissipated in this material in pure and doped state $(5 \% \mathrm{~W}$ and $15 \% \mathrm{Cr})$. The results obtained showed that the doping of vanadium dioxide n-type or p-type reduces the energy dissipated compared to the pure state of this material. When the doping is n-type, the energy dissipated increases as the temperature increases in the infrared spectrum, due to electronic mobility in this material. While the doping is p-type, the energy dissipated decreases compared to the pure state of $\mathrm{VO}_{2}$ because there is an excess of holes created by this type of doping. Therefore, it is obvious to consider the use of the nanoparticles of the vanadium dioxide doped p-type $(15 \% \mathrm{Cr})$, as a suitable candidate for nano additives in fuels that can reduce the energy dissipated due to combustion and optimize energy efficiency. We strongly suggest the manufacturing of storage masses and optical memories based on the vanadium dioxide doped n-type ( $5 \% \mathrm{~W})$, since we can exploit the increase in this dissipated energy as a function of temperature, as a means of increasing the storage speed of information.

\section{Acknowledgements}

This work has been completed in Laboratory of the thin layers and surface treatment by plasma, Ecole Normale Supérieure de Fès, University Sidi Mohamed ben Abdellah. Fez- Morocco.

\section{Conflicts of interest}

The authors declare that there are no conflicts of interest related to this article.

This is an Open Access article distributed under the terms of the Creative Commons Attribution License

\section{References}

[1] Lu PJ, Fang SW, Cheng WL, Huang SC, Huang MC, Cheng HF. " Characterization of titanium dioxide and zinc oxide nanoparticles in sunscreen powder by comparing different measurement methods" Journal of Food and Drug Analysis. (2018);26(3), 1192-200.

[2] Shivakumar N, Madhusudan P, Daniel SCGK. “ Nanomaterials for Smart Food Packaging". Handbook of Nanomaterials for Industrial Applications, (2018),260-70.

[3] Tornero, A.C. Fernández, M. García Blasco, M. Chiquirrín Azqueta, C. Fernández Acevedo, C. Salazar Castro, and S.J. Ramos López. "Antimicrobial Ecological Waterborne Paint Based on Novel Hybrid Nanoparticles of Zinc Oxide Partially Coated with Silver." Progress in Organic Coatings 121 (2018),130-141.

[4] Dhinesh B, Isaac JoshuaRamesh Lalvani J, Parthasarathy M, Annamalai K, "An experimental analysis on the influence of fuel borne additives on the single cylinder diesel engine powered by Cymbopogon flexuosus biofuel", Journal of the Energy Institute, 90(4), (2017) 634-645

[5] Annamalai M, Dhinesh B, Nanthagopal K, SivaramaKrishnan P, Isaac JoshuaRamesh Lalvani J, Parthasarathy $\mathrm{M}$, Annamalai K, "An assessment on performance, combustion and emission behavior of a diesel engine powered by ceria nanoparticle blended emulsified biofuel", Energy Conversion and Management 123 (2016) 372-380.
[6] Morin FJ. "Oxides which show a metal-to-insulator transition at the neel temperature", Phys. Rev. Lett. 3 (1959) 34-36.

[7] C. Kübler, H. Ehrke, R. Huber, R. Lopez, A. Halabica, R.F. Haglund, A. Leitenstorfer, Coherent structural dynamics and electronic correlations during an ultrafast insulator-to-metal phase transition in VO2, Phys. Rev. Lett. 99 (2007) 1-4. doi:10.1103/PhysRevLett.99.116401.

[8] R.J.O. Mossanek, M. Abbate, Optical response of metallic and insulating $\mathrm{VO}_{2}$ calculated with the LDA approach, J. Phys. Condens. Matter. 19 (2007) 346225. doi:10.1088/0953$8984 / 19 / 34 / 346225$.

[9] O.Y. Berezina, a. a. Velichko, L. a. Lugovskaya, a. L. Pergament, G.B. Stefanovich, Metal-semiconductor transition in nonstoichiometric vanadium dioxide films, Inorg. Mater. 43 (2007) 505-511.

[10] J. Cao, Y. Gu, W. Fan, L.Q. Chen, D.F. Ogletree, K. Chen, N. Tamura, M. Kunz, C. Barrett, J. Seidel, J. Wu, Extended mapping and exploration of the vanadium dioxide stress-temperature phase diagram, Nano Lett. 10 (2010) 2667-2673.

[11] Cavalleri, T. Dekorsy, H. H. W. Chong, J. C. Kieffer, R. W. Schoenlein,"Evidence for a structurally-driven insulator- to-metal transition in VO2: A view from the ultrafast timescale", Physical Review B, 70, (2004).

[12] Gmelin Handbook. Section Vanadium Oxides. 1990;16:482. 
Mohammed Zouini, Abderrahim Ben Chaib, Abdesselam Mdaa and El Mehdi el Khattabi/

Journal of Engineering Science and Technology Review 11 (5) (2018) 26 - 34

[13] Paradis, S., Laou, P., Alain, D., "Doped Vanadium Dioxide with Enhanced Infrared Modulation", Technical Memorandum DRDC-VALCARTIER-TM-2007-002, 4 (2007).

[14] L. Kang, Y. Gao, Z. Chen, J. Du, Z. Zhang, H. Luo, Pt/VO2 double-layered films combining thermochromic properties with low emissivity, Sol. Energy Mater. Sol. Cells. 94 (2010) 20782084.

[15] J.B.K. Kana, G. Vignaud, A. Gibaud, M. Maaza, Thermally driven sign switch of static dielectric constant of VO2 thin film, Opt. Mater. (Amst). $54 \quad$ (2016) 165-169. doi:10.1016/j.optmat.2016.02.032.

[16] A. Ben Chaib, A. Mdaa, I. Zorkani, A. Jorio, Optical properties of the Vanadium dioxide, J. Adv. Phys. 8 (2015) 2148-2155.

[17] A. Ben Chaib, A. Mdaa, I. Zorkani, A. Jorio, Optical properties of a thin layer of the Vanadium dioxide at the metal state, J. Adv. Phys. 9 (2015) 1-8.

[18] A. Ben chaib, Z. Mohammed, I. Zorkani, A. Mdaa, A. Jorio, Study of the Absorptance of a Thin Layer of the Vanadium Dioxide, Indian J. Sci. Technol. 9 (2016). doi:10.17485/ijst/2016/v9i48/100111

[19] Béteille, F., Mazerolles, L., Livage, J.: Microstructure and metalinsulating transition of $\mathrm{VO}_{2}$ thin films. Mat. Res. Bull (1999).

[20] Gentle A, Maaroof A, Smith G. "Temperature dependence of optical and transport properties in $\mathrm{VO}_{2}$ with high temperature anomalies". Current Applied Physics, (2008) ,8(3-4):229-32.

[21] Lappalainen J, Heinilehto S, Jantunen H, Lantto V. "Electrical and optical properties of metal-insulator-transition $\mathrm{VO} 2$ thin films. Journal of Electroceramics", (2008) ;22(1-3),73-7

[22] Xiao, D., Kim, K. W., Zavada, J. M.: Imaging properties of a metallic photonic crystal. J. App. Phys, 101(11), 113105, (2007).

23] Golubev, V. G., Davydov, V. Y., Kartenko, N. F., Kurdyukov, D. A., Medvedev, A. V., Pevtsov, A. B., Scherbakov, A. V., Shadrin, E. B.: Phase transition-governed opal-VO2 photonic crystal. App. Phys. Lett, vol. 79, no. 14, pp. 2127-2129, Oct. 2001.

[24] Eyert, V.: The metal-insulator transitions of $\mathrm{VO}_{2}: \mathrm{A}$ band theoretical approach. Ann. Phys (2002).

[25] Benayad, A.: Matériaux monocristallins à forte activité piézoélectrique: élaboration, caractérisation, et application. Thèse de doctorat, Institut National des Sciences Appliquées de Lyon, France (2005).

[26] Z. Liang, L. Zhao, W. Meng, C. Zhong, S. Wei, Tungsten-doped vanadium dioxide thin fi $1 \mathrm{~ms}$ as smart windows with selfcleaning and energy-saving functions, J. Alloys Compd. 694 (2017) 124-131

[27] R. Binions, G. Hyett, C. Piccirillo, I.P. Parkin, Doped and undoped vanadium dioxide thin films prepared by atmospheric pressure chemical vapour deposition from vanadyl acetylacetonate and tungsten hexachloride: the effects of thickness and crystallographic orientation on thermochromic properties, J. Mater. Chem. 17 (2007) 4652.

[28] W. Burkhardt, T. Christmann, B.. Meyer, W. Niessner, D. Schalch, A. Scharmann, W- and F-doped $\mathrm{VO}_{2}$ films studied by photoelectron spectrometry, Thin Solid Films. 345 (1999) 229235.

[29] T.D. Manning, I.P. Parkin, M.E. Pemble, D. Sheel, D. Vernardou, Intelligent Window Coatings: Atmospheric Pressure Chemical Vapor Deposition of Tungsten-Doped Vanadium Dioxide, Chem. Mater. 16 (2004).

[30] L. Zhao, L. Miao, C. Liu, C. Li, T. Asaka, Y. Kang, Y. Iwamoto, S. Tanemura, H. Gu, H. Su, Solution-Processed $\mathrm{VO}_{2}-\mathrm{SiO}_{2}$ Composite Films with Simultaneously Enhanced Luminous Transmittance, Solar Modulation Ability and Anti-Oxidation property, Sci. Rep. 4 (2015) 7000. doi:10.1038/srep07000.

[31] C. Batista, R.M. Ribeiro, V. Teixeira, Synthesis and characterization of $\mathrm{VO}_{2}$-based thermochromic thin films for energy-efficient windows., Nanoscale Res. Lett. 6 (2011).

[32] Klimov, V. A., Timofeeva, I. O., Khanin, S. D., Shadrin, E. B. Ilinskii, A. V., Silva-Andrade, F.'Hysteresis loop construction for the metal-semiconductor phase transition in vanadium dioxide films". Technical Physics (2002), 47(9), 1134-1139.

[33] E Gagaoudakis, E., Kortidis, I., Michail, G., Tsagaraki, K., Binas, V., Kiriakidis, G., Aperathitis, E. "Study of low temperature rfsputtered Mg-doped vanadium dioxide thermochromic films deposited on low-emissivity substrates" Thin Solid Films (2016).

[34] Beteille, F., Livage, J.: Optical switching in $\mathrm{VO}_{2}$ thin films. J. Sol-Gel Sci Technology (1998).

[35] Messiah, A. : Mécanique quantique - volume 1, Dunod, pp. 114 117, pp. 269-270 (1995). 